noises by two different means, $(\mathrm{r}$ ) by vibrating their bodies up and down and hitting their hard "chins" against the ground (Cornitermes similis, Hag.), (2) by sharply crossing one mandible over the other (Mirotermes fur, Silv.). In some species the mandibles have even been modified for the purpose and are asymmetrical. So far as my observations went, the termites only made a noise when there was danger about, such as when I broke open their nests, and then each Cornitermes soldier would tap violently for perhaps half a minute, pause as though listening to the tappings of its neighbours, and then recommence.

Other insects, for example various beetles, will stridulate when attacked. Whether this has the effect of frightening its enemies is difficult to prove. Others again, for example various bugs, only possess functional stridulating organs in the male sex. I believe I am right when I say that some of these have been heard in action when the sexes have been placed together. In spiders a parallel state of affairs is found. I have myself made some of those which possess stridulating organs in both sexes (Aviculariidæ) produce sounds by teasing them and putting them on the defensive, while the only occasion on which I have observed the other type stridulating, in which the organs are present in the male alone (Theridiidæ), is when he is in course of his courtship.

No conclusive experiments have been performed to show that spiders can hear. In the first case, where the spider is merely trying to frighten its enemies, this is not a necessary supposition, but, if the sound-producing organs are to be of any value in courtship, the female must possess some kind of ears, even if they consist merely of a few hairs which vibrate in such a way that she can recognise his presence. Are we to explain the facts to our satisfaction by a series of strange coincidences, or by admitting our inability to discover the organs of hearing in insects and spiders up to the present time?

One has got the impression that Dr. Lutz would like to explain the origin of stridulating organs by the mutational theory. Something of a Lamarckian nature would probably fit the facts more easily.

W. S. Bristowe.

Winnington Hall, Northwich, Cheshire,

$$
\text { March } 23 .
$$

\section{A Method of Determining the Frequency of a Tuning Fork.}

IN an experiment performed in this laboratory on the determination of surface tensions of liquids by the method of ripples, a tuning fork, provided with a dipper and slits on the two prongs, was used to produce the ripples as well as to illuminate the surface of the liquid by intermittent light, obtained by passing a narrow beam of sunlight through these slits and reflecting it on the surface by a plain mirror. It thus became necessary to determine accurately the frequency of the tuning fork with all its encumbrances. Evidently the ordinary graphic method could not be used without introducing more complications and thus altering the frequency, and means were not available of utilising the stroboscopic method. The frequency was, therefore, determined in terms of the length, or the time of vibration, of a simple pendulum hung in front of the slits of the prongs. The light, after passing the two prong slits, passed immediately above the bob of the pendulum, illuminating a small cross which connected the bob to the suspending thread. The light ultimately fell on a drum round which could be wrapped an ordinary photographic film.

On setting the prongs and the pendulum in oscillation, and revolving the drum and at the same time moving it at right angles to the path of the light, a record was obtained on the film consisting of alternate patches of light and darkness, on which at regular intervals, was impressed the shadow of the above-mentioned cross. The frequency of the fork could thus be determined by counting and estimating or measuring the whole and fractional number of bands between two successive impressions of the cross. In the absence of any other mechanical devices, the drum can be set in rapid revolution by the hand and moved across the path of the light, again with the hand. The fork has of course to be electrically maintained.

It may be worth while to direct attention to the fact that in all previous experiments on the determinations of surface tensions by the method of ripples, two forks have been used, one for producing the ripples and the other for illuminating the disturbed surface intermittently, the forks being driven electrically in the usual way so that the vibrations of the two were synchronous. In the present experiment, only one fork was used for producing the ripples as well as making them visible. The values obtained of the surface tensions of water and dilute salt solutions were consistent among themselves and agreed with those given in the Tables, etc. The experiment was carried out by Mr. Jai Kishen, one of my M.Sc. students of last year. J. B. Setr. Physics Laboratory,

Government College, Lahore, February 26.

\section{Change of Linkage in Poultry with Age.}

Two dominant sex-linked Mendelian factors in the domestic fowl are known from the work of W. E. Agar (Journ. Genet., vol. I4, pp. 265-272, I924), J. B. S. Haldane (Sci., vol. 54, p. 663, I92I), and G. S. Serebrovsky (Amer. Nat., vol. 56, p. $57 \mathrm{I}-572$, I922), to exhibit partial linkage during spermatogenesis, as was to be expected if both are carried by the same chromosome. One of these, B, causes barring of the feathers; the other, $S$, causes silver as opposed to gold hackles. We have synthesised five cocks of composition, $\mathrm{BS}$ bs, i.e., receiving both these factors from one parent only, and mated them with bs hens. Thus each of the four possible types of spermatozoon gave rise to a different type of chick. So far 648 chicks have been counted. We find that the linkage between $\mathrm{B}$ and $\mathrm{S}$ becomes progressively weaker with the age of the cocks. In their first, second, and third breeding years respectively these have given $22 \cdot 9 \pm \mathrm{I} \cdot 4$ per cent., $36 \cdot 9 \pm 2 \cdot 9$ per cent., and $47 \cdot 6 \pm 3 \cdot 6$ per cent. of cross-overs. Thus by the third year linkage has practically disappeared.

So far C. B. Bridges (Journ. Exp. Zool., vol. I9, pp. I-I9, I9 15 ) has found a slight increase of crossingover with age in one chromosome only of Drosophila, J. S. Huxley (Brit. Journ. Exp. Biol., vol. I, pp. 2996, I924) a decrease with age in Gammarus, and Castle (Castle, W. E., and Wachter, W. L., Genetics, vol. 9, pp. I-I2, 1924) no change in mice and rats. The variations recorded in plants may be due to temperature and other causes besides age. The change observed by us might be due to diminished rigidity of the chromosomes, increase of the forces tending to break them, or other causes. But it is of interest as pointing to pre-senile changes in the behaviour of the dividing nucleus, and as being the clearest case so far recorded in vertebrates of a change with age of the "germ-plasm" of an individual. The experiment is being continued, but will probably require another two years for completion.

J. B. S. Haldane.

F. A. E. CREW. 